\title{
Impact of Social Media on Administrative Staff Employees in Case of Woldia University
}

\author{
Tizazu Bayih $^{1}$ \\ Department of Information Technology \\ Institute of Technology \\ Woldia University, Ethiopia
}

\author{
Andebet Dessiew ${ }^{2}$ \\ Department of Information Technology \\ Institute of Technology \\ Woldia University, Ethiopia
}

\author{
Semagn Shifere ${ }^{3}$ \\ Department of Computer Science \\ Institute of Technology \\ Woldia University, Ethiopia
}

\begin{abstract}
Now a days Social media has becomes an adaptable and accessible websites that used in day to day communication for the purpose of sharing common ideas and thoughts to share, send and receive different information's based on our business perspectives. Social media users typically access the services of social media via the internet or other web-based technology on their laptops or desktop computers or by downloading applications that extend the functionality of social media and social networks to mobile devices, such as smartphones or tablets. Woldia University have a great fear that administrative might affect adversely because employees are paying more attention towards social media sites. This study tries to identify the impact of social media on administrative staff in Woldia University. On this study we have taking 50(fifty) employees from different administrative staff for the purpose of collecting the relevant information, analyzing data and interpreting. The main focusing is on administrative staff employer unintentionally it has impacts on customer services and responses due to wastage of time and addictions.
\end{abstract}

Keyword:- Social Media Networking, Administrative Employee, Impacts.

\section{INTRODUCTION}

Technology development made the learning easy for the students. Development of smart phones, internet accessibility and various applications facilitated the students to learn anywhere and anytime. Social media has become an integral part of the student's life [1]. Social Network Service is also known as SNS. A SNS is an online service platform, or site that focuses on facilitating the building of social networks or social relations among people who, for example, share interests, activities, backgrounds, or real-life connections [2]. SNSs such as Facebook, Twitter works like this. Adolescents who become members of these SNSs communities, they will firstly get a personal profile which will show their personal information including the name, job, photo, relationship status, religion, hobbies and so on. Then networks of friends are made and other users can then click on their profiles and traverse ever broadening social networks [3].
According to [1] have defined the concept of social media as "a group of internet-based applications that build on the ideological and technological foundations of web 2.0 and that allow creation and exchange of user generated contents". Social media can be considered as an information technology platform in which user communities can search their network, post the experiences and construct the relationships for varies reasons.

The most popular websites of social media users are Facebook, Twitter, Viber, Telegram, YouTube, imo and the associated messengers such as Facebook Messenger. Social networking represents a social structure that displays the different settings of social actors individuals, communities, and organizations and encompasses the social interactions and communications of those social actors. Technological innovation has resulted in both positive and negative changes in the discussion of culture and society [4]. Ultimately, similar to any powerful platform or advancement in innovation, social media and networking sites offer both adverse and productive features to the community, and the influence of social media and social networking sites have had a significant impact on students during their transition to adulthood [5].

Social networking sites are small virtual villages. They operate as pools or collects for compatible users. They operate like a bar or a bookstore, a meeting place orbiting a set of ideals. This is apparent just in the age demographic which frequently visits specific sites [6].

According to [7] "social media" is used somewhat loosely to describe an array of new Web 2.0 platforms. Although they are not always clearly distinguished in the literature, the interactivity associated with "social media" should be differentiated from more generalized forms of online user engagement. For instance, many websites invite users to input their own information, customize the layout and look of a page, prioritize certain kinds of content, or keep track of their own online activities over time. 


\section{Statement of the problem}

Even though social media has a great positive on day to day human life for the purpose sharing and communicating from one to others. As like as it has problems on government organization. Most of employees are killing their time and organization time, searching and posting unethical things, The other problem is employees does not give emphasis/concentration for customers due to using and wasting their time on social media, in this reason customers have negative attitudes on organizational services. Therefor this study is tries to assess and investigate the issues of the impacts of using social media and in woldia university administrative staff.

\section{$>$ Research Questions}

The study was tries to address horizontally and vertically questions of what are the impacts of social media, which social media employees are mostly using and what are the actions to be taken to minimize impacts of Social media on woldia university administrative staff.

\section{Research Objectives}

The objectives of this study were to assessing and investigate the factors which is concern using social media and also evaluating customer satisfaction in woldia University administrative staff.

\section{Scope of the study}

The main intent of the study is to assess and investigate the impacts of social media on woldia university administrative staff. the research is only concerned with Social media networking (SMN) Facebook, telegram, you tube and other social media usage like messenger and imo, Instagram.

\section{RESEARCH METHODS}

\section{A. Description of the study area}

Online Social Media Networks have gained a tremendous popularity among people all around the world, especially university administrative staff employees. As social media site is a vital part in today's university administrative staff employees, it has also a negative impact. Woldia University was established in 2004 E.C. Now it has two campuses namely main campus and Mersa campus. According to university annual report there are 685 active administrative employees. In this study we are clearly assess the impacts of social media on the university administrative staff employees.

\section{B. Nature and Types of Data and Research Design}

The descriptive survey was used for this study in which a blend of both quantitative and qualitative data was collected and analyzed.

\section{Data Collection Techniques and Procedures}

The questionnaires were randomly distributed among finance and purchasing, registrar and alumni office, human resource management system office, student service office and organizational development office. The descriptive data analysis was carried out to analyze ten main variables to address the research questions. The Statistical Package of Social Sciences (SPSS) software and Microsoft Excel package were used to analyze the data. The results are presented with frequencies, percentages and mean values. The sample size contains fifty (50) and they are divided 10 different variable/categories as follows.

\begin{tabular}{|c|c|c|c|}
\hline SN & Variable name & No of respondents and frequencies & Percentage \\
\hline \multirow[b]{2}{*}{1.} & \multirow{2}{*}{ Your Sex } & Male(30) & $60 \%$ \\
\hline & & Female(20) & $40 \%$ \\
\hline \multirow[b]{5}{*}{2.} & \multirow{5}{*}{ Under what office You working } & Finance and Purchasing office (10) & $20 \%$ \\
\hline & & Registrar and Alumni office(10) & $20 \%$ \\
\hline & & Human resource management system(10) & $20 \%$ \\
\hline & & Student Service Office (10) & $20 \%$ \\
\hline & & Organizational Development office (10) & $20 \%$ \\
\hline \multirow[b]{3}{*}{3.} & \multirow{3}{*}{ Duration worked on Institute } & 0 to 3 years $(20)$ & $40 \%$ \\
\hline & & 4 to 6 years $(20)$ & $40 \%$ \\
\hline & & 7 to 9 years $(10)$ & $20 \%$ \\
\hline \multirow[b]{2}{*}{4.} & \multirow{2}{*}{$\begin{array}{l}\text { Have you using Social Media } \\
\text { Networking }\end{array}$} & Yes(46) & $92 \%$ \\
\hline & & $\mathrm{No}(4)$ & $8 \%$ \\
\hline \multirow[b]{4}{*}{5.} & \multirow{4}{*}{ Which Social media is Mostly Used } & Facebook(15) & $30 \%$ \\
\hline & & Telegram(10) & $20 \%$ \\
\hline & & Youtube(10) & $20 \%$ \\
\hline & & Any SMN(15) & $30 \%$ \\
\hline \multirow[b]{3}{*}{6.} & \multirow{3}{*}{$\begin{array}{c}\text { How Much Time you Spent on } \\
\text { Working Hours }\end{array}$} & 0 to 3 Hours $(25)$ & $50 \%$ \\
\hline & & 4 to 6 Hours(15) & $30 \%$ \\
\hline & & 7 to 9 Hours $(10)$ & $20 \%$ \\
\hline
\end{tabular}


ISSN No:-2456-2165

\begin{tabular}{|c|c|c|c|}
\hline \multirow[b]{4}{*}{7.} & \multirow{4}{*}{$\begin{array}{l}\text { For what purpose you use Social Media } \\
\text { Networking }\end{array}$} & Communication/ chatting information(25) & $50 \%$ \\
\hline & & Uploading and downloading materials (5) & $10 \%$ \\
\hline & & Browsing and accessing latest information (5) & $10 \%$ \\
\hline & & Multiple purpose (15) & $30 \%$ \\
\hline \multirow[b]{2}{*}{8.} & \multirow{2}{*}{$\begin{array}{c}\text { Does it have negative impacts on } \\
\text { organization }\end{array}$} & Yes (41) & $82 \%$ \\
\hline & & $\mathrm{No}(9)$ & $18 \%$ \\
\hline \multirow[b]{4}{*}{9.} & \multirow{4}{*}{$\begin{array}{l}\text { what type of the impacts does occur on } \\
\text { organization on your opinion }\end{array}$} & Killing their and organization time(9) & $18 \%$ \\
\hline & & Employee have less concentration on their task(20) & $40 \%$ \\
\hline & & $\begin{array}{c}\text { Organizational information will be Posted } \\
\text { unethically(6) }\end{array}$ & $12 \%$ \\
\hline & & Customers fill negative attitudes due to service(15) & $30 \%$ \\
\hline \multirow[b]{4}{*}{10.} & \multirow{4}{*}{$\begin{array}{l}\text { What was your recommendation to } \\
\text { minimize the impacts of SMN }\end{array}$} & Creating awareness for employees(15) & $30 \%$ \\
\hline & & Lockdown SMN in working hours(20) & $40 \%$ \\
\hline & & Setting rule for Social media usage(10) & $20 \%$ \\
\hline & & $\begin{array}{c}\text { Preparing guideline how employees use SMN on } \\
\text { working hours }(5)\end{array}$ & $10 \%$ \\
\hline
\end{tabular}

Table 1:- Sample Data sets

\section{ANALYSIS AND RESULT OF DATA}

According to sampling we are addressed ten (10) main questions categorized under demographic information, identifying employees on Social media and social media networking ideal questions. From the total 50 administrative employee respondents which is $60 \%$ of male and $40 \%$ of Female respondents from administrative staff. The study area is mainly focus on finance and purchasing office employees (20\%), registrar and Alumni office (20\%), Human Resource management office (20\%), student service office (20\%), organizational development office (20\%) employees and most of selected respondents are working from 0 to 6 years on organization.

\section{Result 1: Have you using social media networking?}

In order to address the questions the impacts of social media networking on administrative employee on Woldia University, we are identifying social media networking usages, from the total 50 respondents $92 \%$ of respondents are using social media networking.

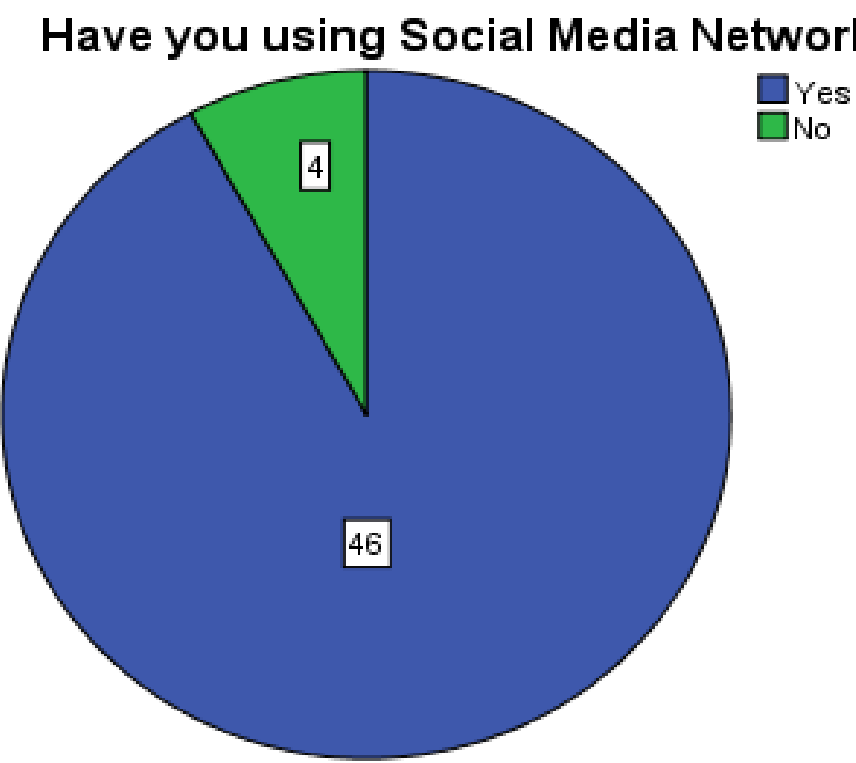

Fig 1:- usage of Social Media Networking

Result 2: which social media is mostly you used?

As figure 2 below shows, from a sample of 50 Administrative employee we found that most of employee respondents are used one or more other social networking site. The social media networking sites that employees used for communication/chatting information, Uploading and downloading materials, browsing and accessing information and for multiple purpose included Facebook, Telegram, YouTube and any social media networking. 


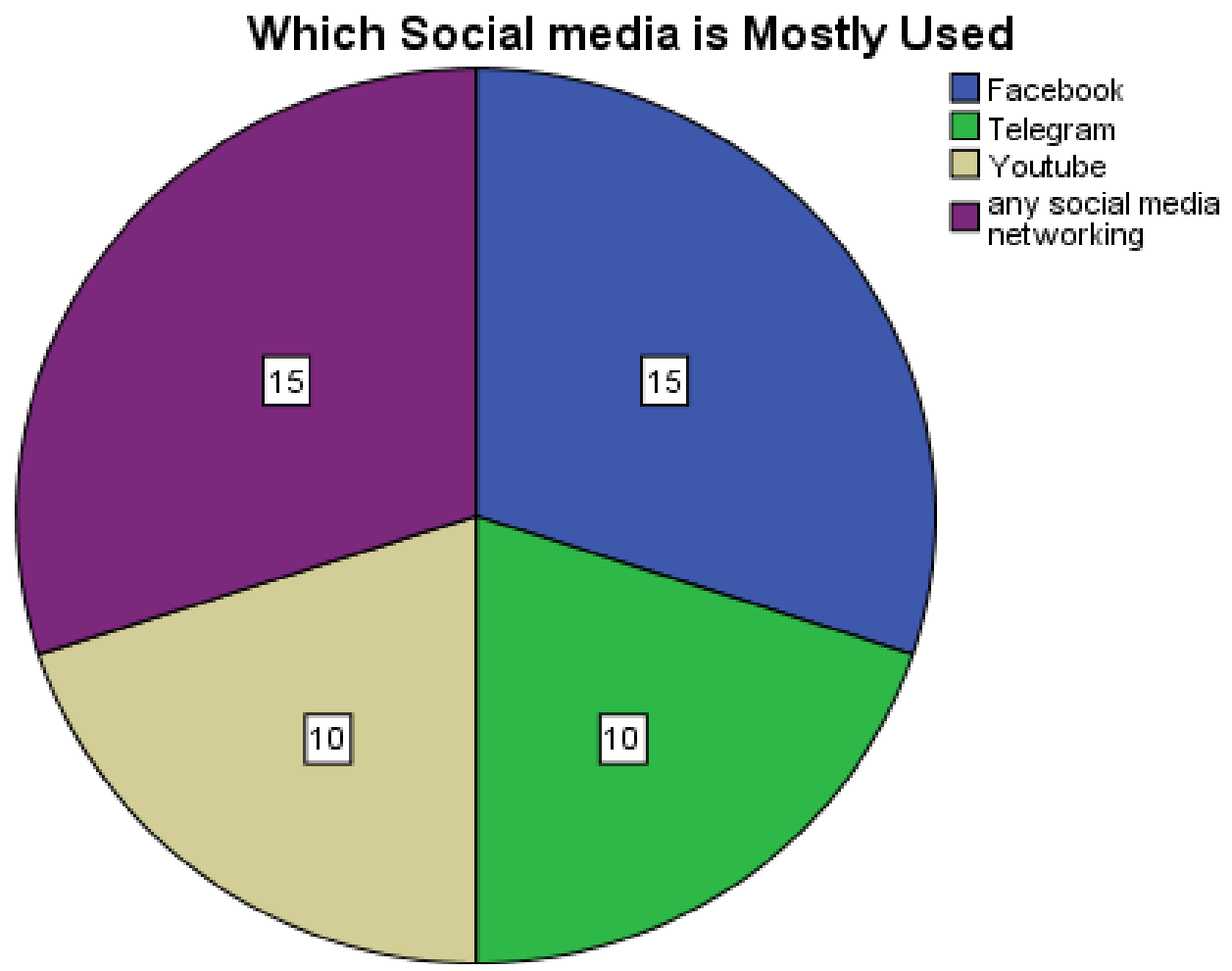

Fig 2:- Most Social Media Networking Sites

Most of Administrative employees are used one or more social media networking for the purpose communication/chatting information, Uploading and downloading materials, browsing and accessing information and for multiple purpose. Most of respondents are used Facebook and multiple social media networking and they are spent their and organizational time as follows in table 2

\begin{tabular}{|c|c|c|c|c|c|}
\hline \multicolumn{2}{|c|}{} & Frequency & Percent & Valid Percent & Cumulative Percent \\
\hline \multirow{3}{*}{$: \frac{7}{\pi}>$} & 0 to 3 Hours & 25 & 50.0 & 50.0 & 50.0 \\
\cline { 2 - 6 } & 4 to 6 hours & 15 & 30.0 & 30.0 & 80.0 \\
\cline { 2 - 6 } & 7 to 9 Hours & 10 & 20.0 & 20.0 & 100.0 \\
\hline
\end{tabular}

Table 2:- Spending time on working hours

Result 3: Does it have negative impacts on organization and individuals. if so what are the impacts of social media

According to the impacts of social media networking on individuals and organization levels $82 \%$ of respondents are agreed that social media have negative impacts on individuals and organization level and the rest of $18 \%$ respondents said that there is no drawbacks when we are using social media anywhere, anytime and anyplace. also the study is analysis the respondents perspective due to type of impacts and said as discuss on figure 3 that $18 \%$ of respondents said that it has time killer on individual and organizational factors, $40 \%$ of respondents are less concentration on their task due to given more emphasis to social networking, $12 \%$ of respondents said that also it has great negative impact to posting organizational information unethically and the rest of $30 \%$ of respondents are agreed using social media networking on organizational working hours has impact on customer service. 


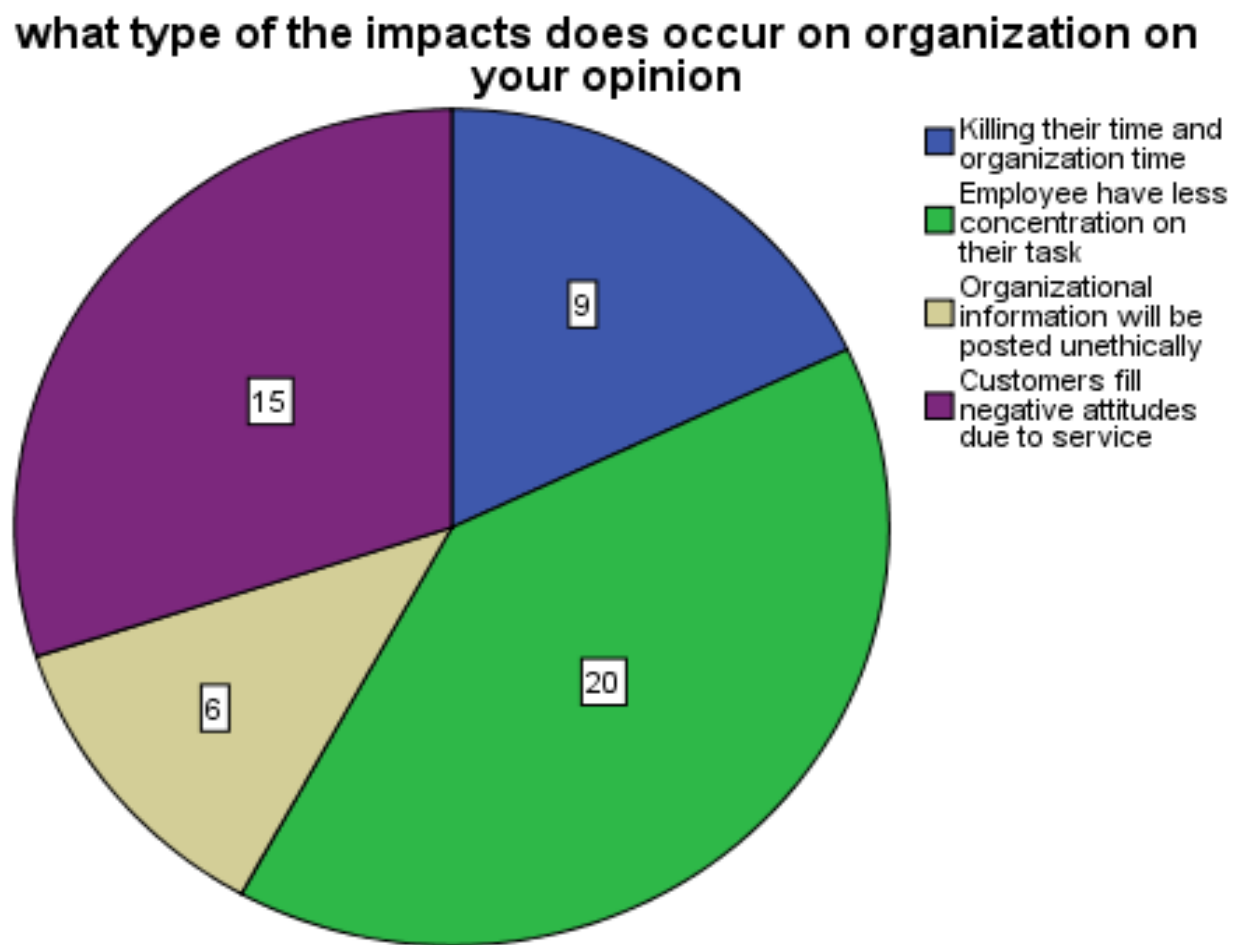

Fig 3:- Impacts of SMN on individuals and organization

Result 4: what was your personal recommendations to minimize the impacts of social media on Woldia University

According to the impacts of social media networking (SMN) administrative staff employees are setting their assumptions to minimize the impacts. $40 \%$ of the respondents are assured lockdown social media networking websites, $30 \%$ of the respondents are argue creating awareness for employees, $20 \%$ setting rule based how the employees use social media and $10 \%$ of the respondents are also argue preparing guideline for employees to use Social media networking. As figure 4 shows Most of respondents are argues for the purpose of minimizing the impacts of Social Media networking(SMN) lockdown the university social media networking service is better.

\section{What was your recommendation to minimize the impacts of SMN}

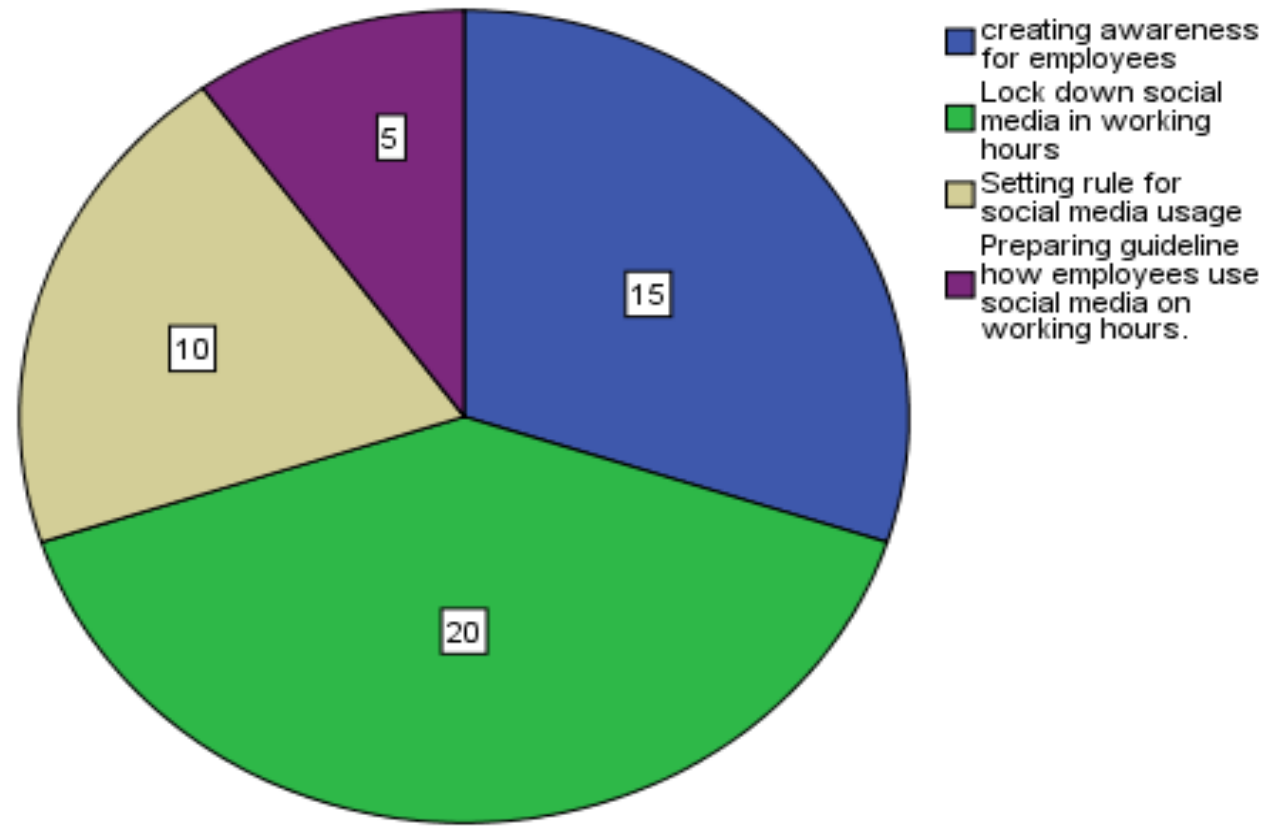

Fig 4:- Assumptions to minimize impacts of Social media 


\section{CONCLUSIONS}

The purpose of this research was to find out the impacts of social media networking on Administrative staff employees in case of Woldia University. According to survey we have finding most of employees are uses Social Media networking (SMN) up to 3 hours (50\%) of respondents have less concentration on organizational activity due to more emphasis to social media than organizational activity and also customers fill negative attitudes due to organizational service.

Finally, to minimize the impacts of Social media Networking (SMN) it is important lockdown the most popular social media sites on working hours especially Facebook, telegram, YouTube and other social media except academic sites for the purpose decrease the negative impacts on personal and organizational development.

\section{REFERENCES}

[1]. Radhika Thapoir Soni, Dr.Vidhi Tyagi, "Factors affecting use of Social Media by students- A study of Delhi NCR," International Journal for Research in Engineering Application \& Management (IJREAM), Vols. Vol-04, no. Issue-11, pp. 2-7, Feb 2019.

[2]. H. B. J. C. E. JA. Paul, "Effect of online social networking on student academic performance. Computers in Human Behaivior," International Journal for Research in Engineering Application \& Management (IJREAM), vol. 26, pp. 3-8, 2012.

[3]. J. M. J. W. T. H. F. C. Madge, "cial integration and informal learning at university: Learning, Media and Technology," pp. 141-155, 2009.

[4]. Jaffar Abbas, Jaffar Aman, Mohammed Nurunnabi, Shahar Bano "The Impact of Social Media on Learning Behavior for Sustainable Education: Evidence of Students from Selected Universities in Pakistan," MDPI Sustanability, March 2019.

[5]. L. A. D. Z. Zhu, "Social media and culture in crisis communication: McDonald's and KFC crises management in China," International Journal of Scientific and Research Publications, vol. 2017, p. 487-492.

[6]. Yirga. Yayeh, "The Impact of Social Media's on Technology Students in Assosa University,Ethiopia," The International Journal research Publications, vol. Volume: 04 , no. Number: 11, pp. 2-5, September2015.

[7]. Kawunan Wulison, Jinnifer Keelan, REBECCA SCHEIN, "EFFECTIVENESS OF THE USE OF SOCIAL MEDIA ON PUBLIC HEALTH," Canada. 